\title{
Assessment of Factors Affecting Attendance of Antenatal Care in Kagote Health Center III, Kabarole District, Uganda.
}

\author{
Margaret Apiso a,1,2

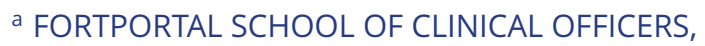 \\ FORTPORTAL, UGANDA
}

\begin{abstract}
\end{abstract}

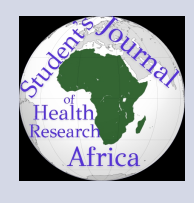

Background: ${ }^{a}$

Antenatal care is generally thought to be an effective method of improving outcomes in pregnant women and their babies, although many specific Antenatal Care practices have not been subject to rigorous evaluation

Methodology:

A descriptive cross-sectional study was carried out in Kagote HCIII aimed at assessing the factors affecting ANC attendance in the Kabarole district. Using a convenience sampling method, Kagote HCIII was chosen by the random sampling method. A sample of 100 respondents was interviewed. Questionnaires were used to obtain data from the individuals and these were in form of closed and open-ended questions.

Results:

The majority of the respondents $92(92 \%)$ used ANC information in subsequent pregnancies. $48(48 \%)$ said that multiparous women did not need to attend ANC if they were healthy while $12 \%$ were not sure. Challenges include long distance from the ANC clinic 32(13\%), harsh health service providers $8(3 \%)$, lack enough support from husbands 22(9\%), segregation and discrimination 12(5\%), negative attitude towards ANC 16(7\%), high transport costs $37(15.4 \%)$, lack of enough money $43(18 \%)$, lack of enough time $10(4 \%)$, too much workload at home $16(7 \%)$, long waiting time $20(8.3 \%)$, unavailability of some drugs at times $24(10 \%)$.

\section{Conclusion and recommendation:}

The factors affecting ANC attendance in Kagote HCIII are; age, occupation, education level, marital status, address, the number of health workers, their cadre, skill, authority, knowledge, nature, the services they and how they offer them, availability of incentives like drugs, multiparity, the order of pregnancy and the challenges mentioned above.

There is a need for the $\mathrm{MOH}$ to continue sensitizing people about the importance of ANC attendance, outreaches by the health facility to the community to offer the service and encourage attendance, a collaboration between the health facility and the village health team continued health education of women of reproductive age about ANC and its attendance.

\footnotetext{
a Email: apisomargret@gmail.com

Received: 9th/12/2020 Accepted:

11th/02/2021 Journal of Obstetrics and

Gynecology
} 


\section{Background}

Antenatal care is generally thought to be an effective method of improving outcomes in pregnant women and their babies, although many specific Antenatal Care practices have not been subject to rigorous evaluation (Jennifer et al., 2009). Antenatal care is a key strategy to improve maternal and infant health. (Christopher et al., 2013). Antenatal care is a key element of the package of services aimed at improving maternal and infant health.

In light of evidence from a 2001 systematic review, the World Health Organization began promoting a new model of ANC for low-income countries, moving away from the traditional model, based on 'reduced but goal-oriented clinic visits; that is, 'focused' ANC, consisting of (at least) four visits to a health facility during an uncomplicated pregnancy. (Christopher, 2013).

World Health Organization estimates that every year approximately 8 million women endure pregnancy-related complications and around half a million die as a result. According to a WHO report, (2010), Almost 9 million children die every year, of which 4 million new born babies die within the first month of life. Also, 3.3 million babies are dead. (St. Mary's Midwifery Training School- 2013). However, linkages with higher-level health services need to be strengthened since the vast majority of women are still giving birth at home and without a skilled attendant.

Nearly 4 million neonatal deaths and 500,000 maternal deaths are estimated to occur annually in the world. About $98 \%$ of these occur in low and middle-income countries. Antenatal care has been proven to be effective in improving pregnancy outcomes through early detection and management of pregnancy complications. (Toan, 2012).

The minimum ANC visits recommended by WHO (4 visits) was possible for less than about a third of the pregnant women in Sub Sahara Africa (SSA) countries. (Yifru et al., 2014). The causes of maternal deaths preventable by ANC and delivery care include; pre-eclampsia, eclampsia, obstructed labor, malaria, anemia, ectopic pregnancy, $\mathrm{PPH}$, postpartum sepsis. The Health Sector Strategic Investment Plan (HSSIP) has no written reports about antenatal care in Kagote Health Center III (HC III).

Twelve of the twenty-five countries that achieved $50 \%$ and more coverage of pregnant women with at least 4 ANC visits included SSA countries. The minimum antenatal care visits recommended by WHO (4 visits) was possible for less than about a third of the pregnant women in some SSA countries like Niger (5\%), Ethiopia (19\%), Chad (23\%), Burundi (33\%), Mali and Rwanda (35\% each). (Yifru, 2014)

Although scientific debate concerning the design of ANC continues, research suggests that in low-income countries particularly SSA, pregnant women do not often receive the recommended ANC. Moreover, amongst the sub-Saharan countries, the trend over the last 10 to 20 years in the proportion of women making at least 4 visits varies markedly: DHS survey data indicate that in West Africa, 8 to 10 countries have illustrated increases, whereas, in Southern and East Africa, 6 of 11 countries have experienced declines. (Christopher et al., 2013). Despite the increase in staffing levels, the availability of EMHS, Reproductive Health $(\mathrm{RH})$ indicators is still below the HSSIP targets. The percentage of pregnant women attending at least 4 ANC sessions only slightly increased from $32.4 \%$ in $2013 / 14$ to $36.6 \%$ in $2014 / 15$ (target was $60 \%$ ). The percentages of pregnant women attending ANC sessions in respect to districts; Gulu $-45.2 \%$, Jinja -42.3\%, Kaberamaido -23.0\%, Rukungiri- 42.6\%, Kabarole 46.6\%. (Annual Health Sector Performance Report (AHSPR) 2014/2015).

According to the report, only $8 \%$ of rural women in Uganda received ANC from a doctor. Regionally, South-Western were more likely to receive skilled care (20\%), than Eastern women (3\%), while only $2 \%$ of women in Karamoja were reported to seek the same. It was reported that women in Uganda tend to seek ANC very late- $37 \%$ attending for the first time at 6 months or more. (Uganda Bureau of Statistics, 2007).

According to Kagote $\mathrm{HC}$ III records $56 \%$ of pregnant women attend the 4 four visits of ANC in 2015. This is low compared to the target of $60 \%$. Due to this low attendance, it is important to find out the factors affecting the attendance of the four ANC visits in Kagote $\mathrm{HC} \mathrm{III} \mathrm{in} \mathrm{the} \mathrm{Kabarole} \mathrm{district.}$

Kabarole district is found in the mid-western part of the country - Uganda, approximately 290 kilometers west of the capital city of Uganda - Kampala. It's bordered by Ntoroko district to the North, Kibale district to the Northeast, Kasese to the South, and Bundibugyo district, across the mountains to the West, Kyenjojo to the East and Kamwenge to the South East. In August 2014, the national population census put the population of Kabarole at 
54,275 . Antenatal care (ANC) is the care offered to women during pregnancy aiming at proper delivery of the baby and preventing any serious complications during or after delivery on both the mother and the baby. The activities involved in ANC include measurement of body weight and height, blood pressure; symphysis- fundus measurement, abdominal circumference, fetal heart rate, vaginal examination, investigations like urine protein test, blood tests for anemia and HIV: giving tetanus vaccination, folate combined iron supplement; malaria chemoprophylaxis and prenatal medical consultation.

\section{METHODOLOGY}

Study area

The study was carried out in Kagote health center III, Fort Portal Municipality, Kabarole District, Western Uganda, and details of the District are shown in the map and table below:

Figure 1: Map of Uganda showing the location of Kabarole District.

Source: district planning unit- Kabarole 2010/2011-2012/2013

From table 1 above, the Kabarole district has three counties, twenty-two sub-counties, 85 parishes, and 750 villages.

\section{Study design}

The research used descriptive and crosssectional study applying both qualitative and quantitative strategies. Qualitative explored the view of the respondents and quantitatively explored the numerical findings concerning factors affecting ANC attendance in Kagote HC III. Face to face interviews using a structured questionnaire were the data collection method.

\section{Study population}

The study was focused on women of childbearing age.

\section{Sampling procedure}

Random sampling was done and only women of childbearing age were selected into the sample.

\section{Sample size determination}

The sample size was determined using Kish Leslie's formula: $\quad n=(\bar{z} 2 p(1-p)) / d 2$

Where;

$\mathrm{n}=$ desired sample

$\mathrm{z}=$ standard normal deviation usually set as 1.96 corresponding to $95 \%$ $p=$ proportion in a population estimated to have a particular characteristic given as $56 \%$ which is equivalent to 0.56

$d=$ the degree of error set at a range of $0.05 \_0.1$

$n=([1.92] 2 \times 0.56 \times 0.44) /[0.05] 2$

Thus, $\mathrm{n}=378$

However, due to financial constraints and time, the study enrolled 100 respondents.

\section{Sampling unit}

The investigator used a woman of childbearing age as the sampling unit.

\section{Study variables}

\section{Independent variable}

The independent variable of the study was the attendance of ANC.

\section{Dependent variables}

The dependent variables for the study were demographic data, workers, the service delivery of health workers, their number, their level of training, availability of materials to be used in ANC, and the ANC attendance practice of mothers.

\section{Data collection and management}

Data collection procedure

Data was collected using a pretested questionnaire. The questionnaire contained both openended and closed-ended questions. Two research assistants were chosen and trained depending on their willingness to participate in the study and ability to understand, speak, and interpret the local languages. The respondents were met at the health center and each was requested to consent to participate as a respondent in the study.

\section{Data management}

Collected data was cross-checked for errors and corrected it, then analyzed. After this, the questionnaire was kept under a lock and key for future reference.

\section{Data collection tools}

A pen, a clipboard, and a simple electronic calculator were used to ease data collection through writing, backing the questionnaire, and computing the percentages.

\section{Inclusion and exclusion criteria Inclusion criteria}

- All women aged between 18 to 49 years attending Kagote $\mathrm{HC}$ III during the time of data collection were included in the study.

- Only those who consented to participate in the study were included.

- Only those with a sound mind at the time of data collection were included in the study. 


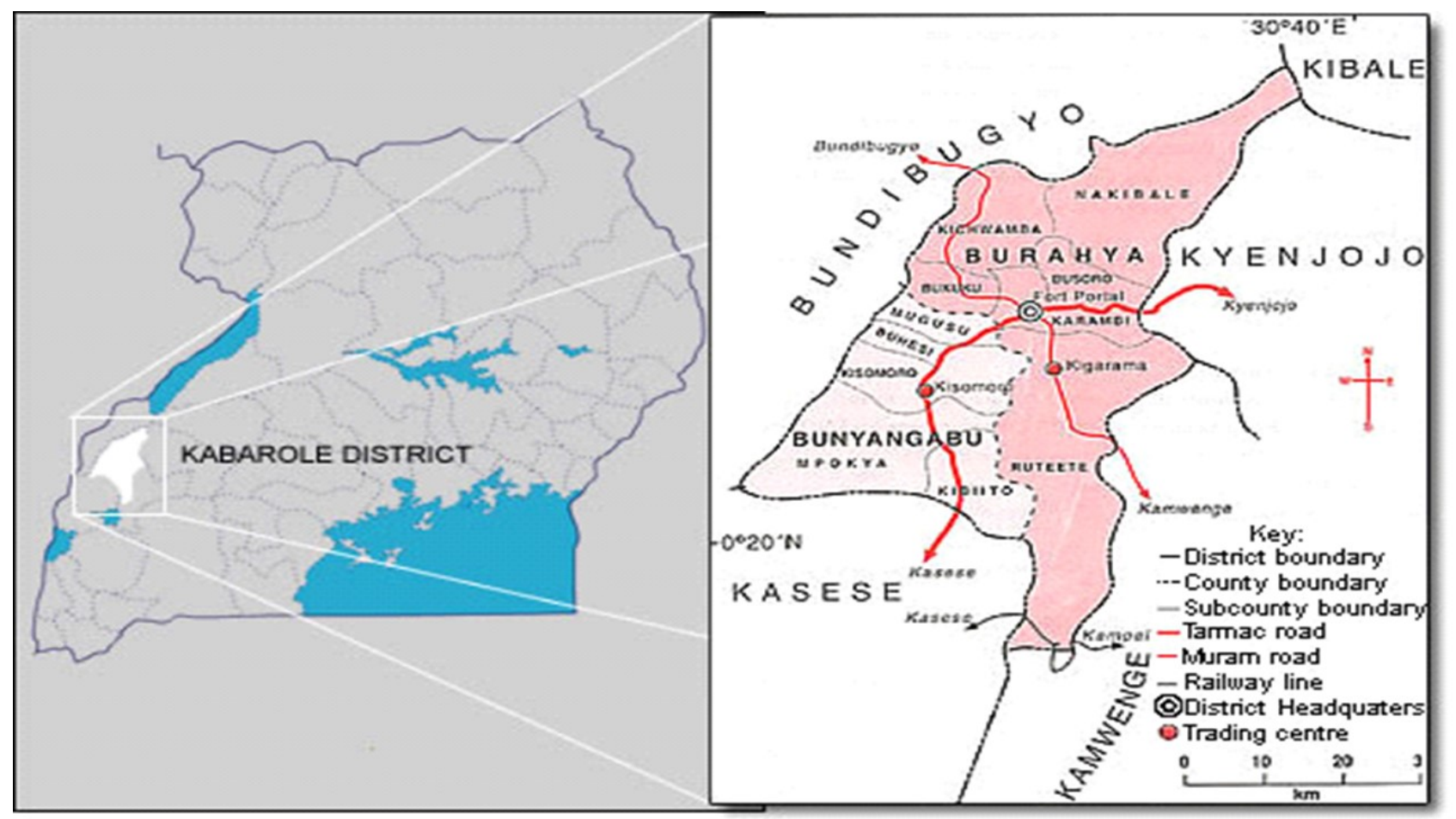

Figure 1. Shows details of kabarole district

\section{Exclusion criteria}

- All women below 18 years and above 49 years were excluded from the study.

- All women who did not consent were excluded from the study.

\section{Ethical considerations}

The research proposal was approved by the principal of the School of Clinical Officers Fort Portal, who then provided a research request letter. This was presented to the clinical officer-in-charge of Kagote $\mathrm{HC}$ III to permit the investigator to carry out the research project at her health unit. The investigator explained the purpose of the research to the participants and those who were willing to participate signed a consent form. Respondents' names were not written on the questionnaire though a unique numbering was used to enable better organization. Withdrawal from the research study was free with no effect on health service provision on participants. The data collected was kept confidential.

\section{RESULTS}

\section{Demographic characteristics}

Demographic characteristics of the respondents

$N=100,(n=25)$
Referring to table 2, twenty-eight percent (28) of respondents were between the ages of 25-29 years, and only $4 \%$ (4) were between $45-49$ years. Forty percent (40) of the respondents were Batooro while at least $16 \%$ (16) were Banyankole. Thirty-six percent (36) belonged to the catholic faith, and the least $12 \%$ (12) were Moslems. On occupation, $32 \%$ (32) of the respondents were housewives, and $16 \%$ (16) were civil servants. Sixty percent (60) of the respondents were married, and 2(2\%) of them were widowed. Forty (40\%) of the respondents had attained a secondary level of education while $12(12 \%)$ never attended formal education. Fifty-six (56\%) of the respondents lived in villages, and a significant number 12(12\%) lived in large towns.

\subsection{Provider- related factors affecting ANC attendance}

Figure 2: Number of health workers offering ANC services at Kagote $\mathrm{HC}$ III.

$N=100,(n=25)$

Fifty-six percent (56) of respondents reported that 2 health workers offered ANC services while twenty percent (20) reported 1 health worker did so.

\section{ANC services offered at Kagote HC III} $N=100,(n=240)$ 
Assessment of Factors Affecting Attendance of Antenatal Care in Kagote Health Center III, Kabarole District, Uganda.

Table 1. Kabarole District local government administrative units as of $\mathbf{1}^{\text {st }}$ July 2010

\begin{tabular}{|c|c|c|c|}
\hline County & $\begin{array}{l}\text { Sub-counties/Town } \\
\text { councils/Division }\end{array}$ & Parishes & $\begin{array}{l}\text { Number of } \\
\text { villages }\end{array}$ \\
\hline \multirow[t]{9}{*}{ Burahya } & Bukuku & Karago, Kiguma and Kazingo & 25 \\
\hline & Busoro & Busoro, Mwibaale, Kaswa and Rwengaju & 50 \\
\hline & Kasenda & $\begin{array}{l}\text { Kasenda, Nyabweya, Isunga, Rwankezi, Kasenda } \\
\text { p, and kabata }\end{array}$ & 51 \\
\hline & Karambi & Karambi, Rubingo,Butebe, Rubingo B, Gweri & 60 \\
\hline & Mugusu & Kiboha, Kiraaro, Burungu and Nyabuswa & 43 \\
\hline & Kicwamba & Nyantaboma, Bwanika and Kihondo & 45 \\
\hline & Ruteete & Kyamukoka, Kiko and Rurama & 32 \\
\hline & Kyeitamba TC & Kijura, Kyererezi, Kasaigara and Kahuna & 14 \\
\hline & Hakibaale & Kiburara, Kahangi, Kibasi, Kitule and Kabende & 48 \\
\hline \multirow{10}{*}{$\begin{array}{l}\text { Bun- } \\
\text { yangabu }\end{array}$} & Kisomoro & Lyamabwe,Kicuucu and Kisomoro & 33 \\
\hline & Rubona TC & Rubona and Kahondo & 14 \\
\hline & Karangura & Nyarukamba and Kabango & 12 \\
\hline & Kateebwa & $\begin{array}{l}\text { Bunaiga,Mitandi, Mutumba, Kateebwa, Nsura } \\
\text { and Kyamukube }\end{array}$ & 44 \\
\hline & Kibiito & Mujunju, Kasunganyanja and Kabale & 21 \\
\hline & Kabonero & Kabonero,Bukara and Nyarugongo & 42 \\
\hline & Rwimi & Kaina, Kakooga and Kadindimo & 21 \\
\hline & Buheesi & $\begin{array}{l}\text { Rwesenene, Kiremezi,Kabahango, Nyamiseke, } \\
\text { Kiyombya and Kiboota }\end{array}$ & 64 \\
\hline & Kibiito TC & Central, South, East, West and S/East & 18 \\
\hline & Rwimi TC & Central, West, Nyabwina and East & 19 \\
\hline \multirow{4}{*}{$\begin{array}{l}\text { Fort- } \\
\text { Portal }\end{array}$} & East Division & Bukwali, Kitumba, Njara, Nyakagongo & 36 \\
\hline & & & \\
\hline & South Division & Bazaar, Kasusu and Kijanju & 33 \\
\hline & West & Kagote, Kibimba, Nyabukara, Rwengoma & 24 \\
\hline 3 & 22 sub-counties & 85 parishes & 750 \\
\hline counties & & & \\
\hline
\end{tabular}

Seventy-two (30\%) of the respondents pointed at routine physical examination of a pregnant woman as the major ANC service offered while a significant number 24(10\%) pointed at tetanus vaccination.

Figure 3: Showing how health workers handle pregnant women at the ANC clinic.

$N=100,(n=25)$

From figure 3 above, forty-six percent (46) reported that they were handled well and only $10(10 \%)$ harshly.

\section{Medications offered at the ANC clinic}

$\mathbf{N}=100,(n=138)$

Majority 88 (63.7\%) of respondents reported that they always received the medications and only $2(1.4 \%)$ respondents who reported that they at times never got fansidar.

Figure 4: Characteristics of health workers offering ANC services at the health unit

\section{$\mathbf{N}=100,(n=25)$}

Forty percent (40) reported that the health workers were knowledgeable and a significant number $16 \%$ (16) reported others like supportive, caring. The rest were as shown in figure 4.

Cadre of health workers of health workers offering ANC services at Kagote unit

$$
\mathrm{N}=100,(\mathrm{n}=180)
$$

Most of the respondents 84 (47\%) of the respondents reported that they were worked on by midwives while only $12(7 \%)$ of them reported that nursing assistants offered the service.

\subsection{Other factors affecting ANC attendance}

Figure 5: Whether information mothers have about ANC can help them in subsequent pregnancies 


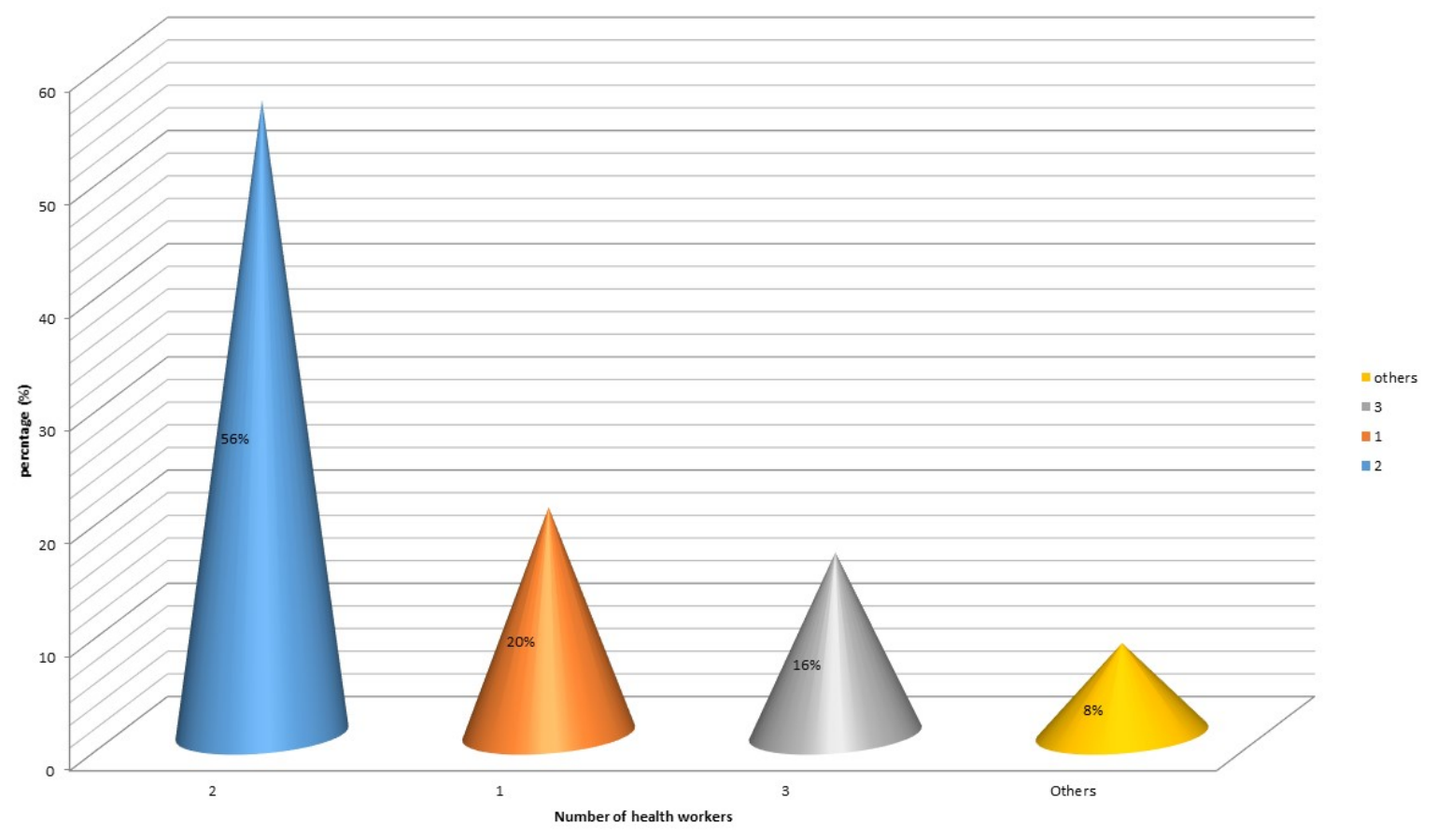

Chart 1. shows number of health workers offering ANC services at Kagote HC III.

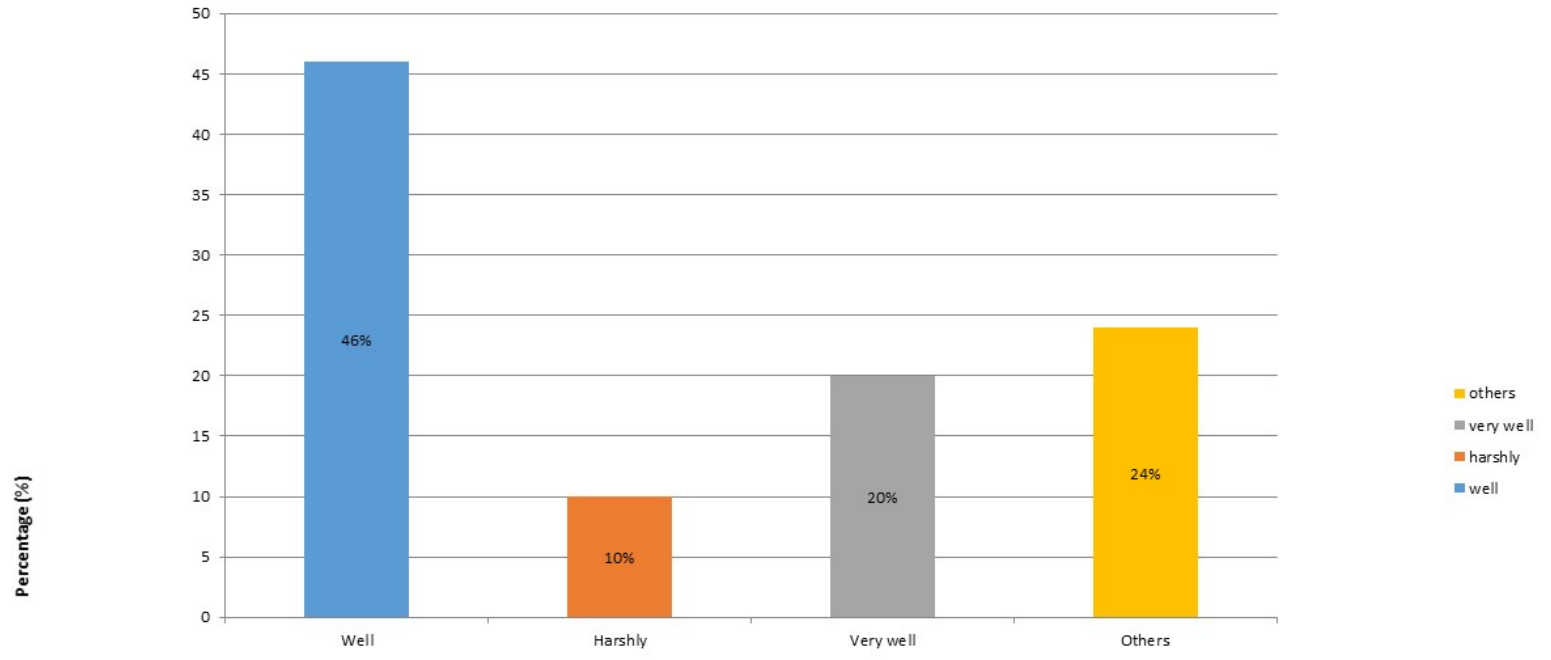

How health workers handle pregnant women

Chart 2. Showing how health workers handle pregnant women at the ANC clinic. 
Assessment of Factors Affecting Attendance of Antenatal Care in Kagote Health Center III, Kabarole District, Uganda.

Table 2. Demographic characteristics of the respondents

\begin{tabular}{|c|c|c|c|}
\hline \multirow[t]{4}{*}{ Variable } & Class (grouping) & Frequency & Percentage (\%) \\
\hline & $15-19$ & 10 & 10 \\
\hline & $20-24$ & 16 & 16 \\
\hline & $25-29$ & 28 & 28 \\
\hline \multirow{7}{*}{$\begin{array}{l}\text { Age ( } \\
\text { years) }\end{array}$} & $30-34$ & 20 & 20 \\
\hline & $35-39$ & 14 & 14 \\
\hline & $40-44$ & 8 & 8 \\
\hline & $45-49$ & 4 & 4 \\
\hline & TOTAL & 100 & 100 \\
\hline & Batooro & 40 & 40 \\
\hline & Bakonzo & 24 & 24 \\
\hline \multirow[t]{5}{*}{ Ethnicity } & Banyankole & 16 & 16 \\
\hline & Others & 20 & 20 \\
\hline & TOTAL & 100 & 100 \\
\hline & Catholics & 36 & 36 \\
\hline & Anglicans & 28 & 28 \\
\hline \multirow[t]{3}{*}{ Religion } & Moslems & 12 & 12 \\
\hline & Others & 24 & 24 \\
\hline & TOTAL & 100 & 100 \\
\hline \multirow{6}{*}{$\begin{array}{l}\text { Occupa- } \\
\text { tion }\end{array}$} & Peasants & 28 & 28 \\
\hline & Civil servants & 16 & 16 \\
\hline & House wives & 32 & 32 \\
\hline & Others & 24 & 24 \\
\hline & TOTAL & 100 & 100 \\
\hline & Married & 76 & 76 \\
\hline \multirow{6}{*}{$\begin{array}{l}\text { Marital } \\
\text { status }\end{array}$} & Single & 6 & 6 \\
\hline & Widowed & 2 & 2 \\
\hline & Divorced & 16 & 16 \\
\hline & TOTAL & 100 & 100 \\
\hline & Primary & 21 & 21 \\
\hline & Secondary & 40 & 40 \\
\hline \multirow{5}{*}{$\begin{array}{l}\text { Level of } \\
\text { education }\end{array}$} & Tertiary & 15 & 15 \\
\hline & Never attended formal education & 12 & 12 \\
\hline & Others & 12 & 12 \\
\hline & TOTAL & 100 & 100 \\
\hline & Village & 56 & 56 \\
\hline \multirow{3}{*}{ Address } & Small town & 32 & 32 \\
\hline & Large town & 12 & 12 \\
\hline & TOTAL & 100 & 100 \\
\hline
\end{tabular}

\section{$N=100,(n=25)$}

Majority of the respondents 92 (92\%) reported that the information they had on ANC could help in their subsequent pregnancies while the minority $8(8 \%)$ disagreed.

Respondents cited that they learnt a lot about pregnancy, got to know how to handle it, and got more experience about it. Those who disagreed cited the fact that pregnancies differ.
Figure 6: Whether multiparous pregnant women to attend ANC N=100, $(n=25)$

From the figure 6 above, nearly half of the respondents $48(48 \%)$ reported that they did not need to attend ANC if they are feeling healthy while only $12(12 \%)$ reported they were not sure.

Showing the order of pregnancy at which pregnant women attend ANC

$N=100,(n=25)$ 
Table 3. ANC services offered at Kagote HC III

\begin{tabular}{lll}
\hline ANC Services offered & Frequency (f) & Percentage (\%_) \\
Routine physical examination of a pregnant woman & 72 & 30 \\
Health education & 40 & 17 \\
Tests like HIV testing, testing for syphilis & 32 & 13 \\
Tetanus vaccination & 24 & 10 \\
Medications like fansidar, folic acid, mebendazole, fefan & 60 & 253 \\
Others & 12 & 5 \\
TOTAL & $\mathbf{2 4 0}$ & $\mathbf{1 0 0}$ \\
Most respondents gave more than one answer & & \\
\hline
\end{tabular}

Table 4. Medications offered at the ANC clinic

\begin{tabular}{|c|c|c|c|c|c|c|c|}
\hline & $\begin{array}{l}\text { Folic } \\
\text { acid }\end{array}$ & $\begin{array}{l}\text { Fe- } \\
\text { fan }\end{array}$ & $\begin{array}{l}\text { Mebenda- } \\
\text { zole }\end{array}$ & $\begin{array}{l}\text { Fansi- } \\
\text { dar }\end{array}$ & $\begin{array}{l}\text { Tetanus } \\
\text { toxoid }\end{array}$ & $\begin{array}{l}\text { Other } \\
\text { drugs }\end{array}$ & $\begin{array}{l}\text { TotaPercentage } \\
\text { fre- }(\%) \\
\text { quency }\end{array}$ \\
\hline Always & 15 & 21 & 11 & 14 & 14 & 13 & $88 \quad 63.7$ \\
\hline Often & 7 & 5 & 5 & 5 & 3 & 7 & $32 \quad 23$ \\
\hline Never & 0 & 0 & 0 & 2 & 0 & 0 & 21.4 \\
\hline I buy them & 0 & 2 & 1 & 4 & 3 & 6 & 1611.5 \\
\hline GRAND & & & & & & 138 & 100 \\
\hline \multicolumn{8}{|l|}{ TOTAL } \\
\hline \multicolumn{8}{|l|}{ Many of th } \\
\hline
\end{tabular}

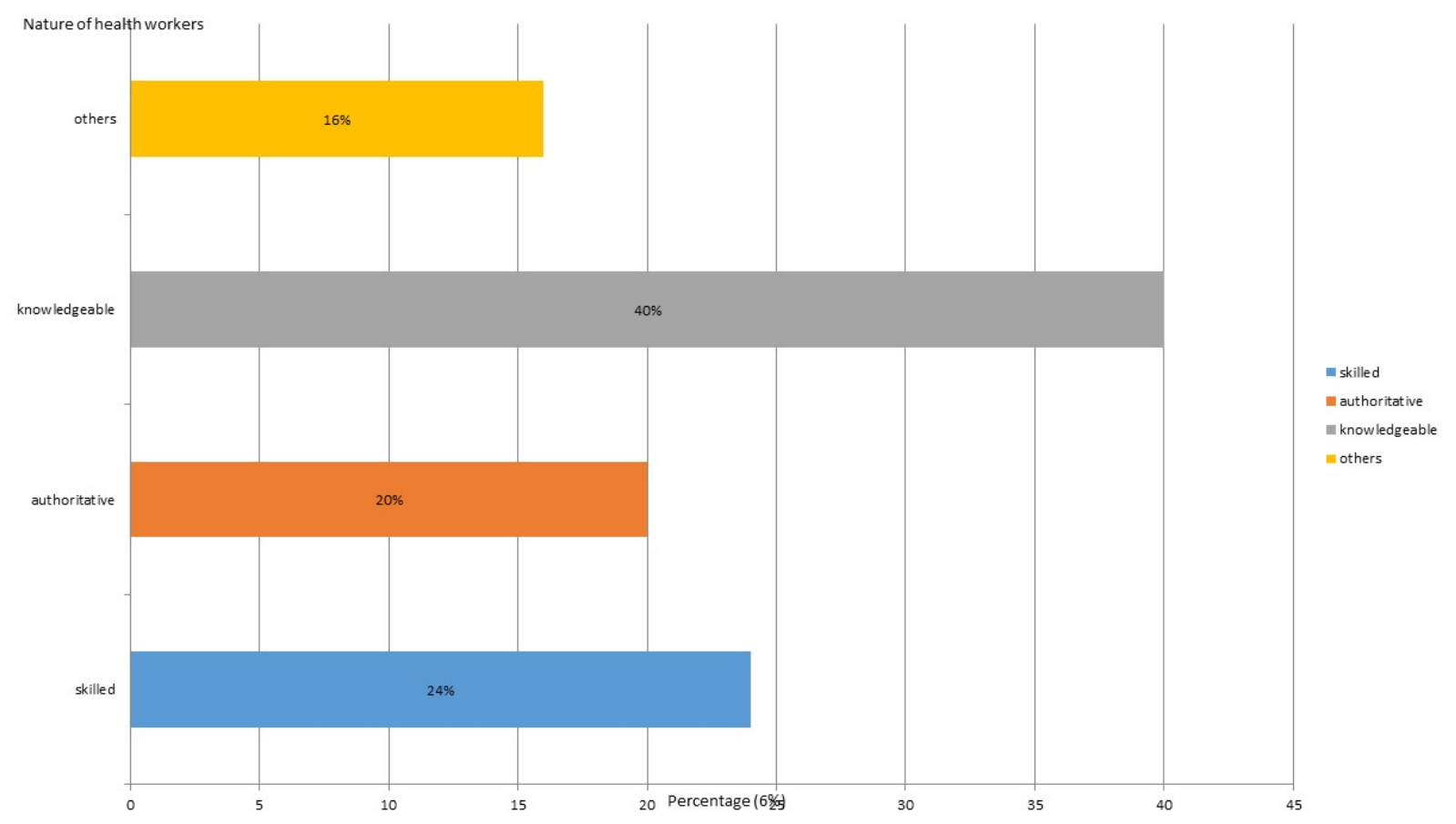

Chart 3. Characteristics of health workers offering ANC services at the health unit 


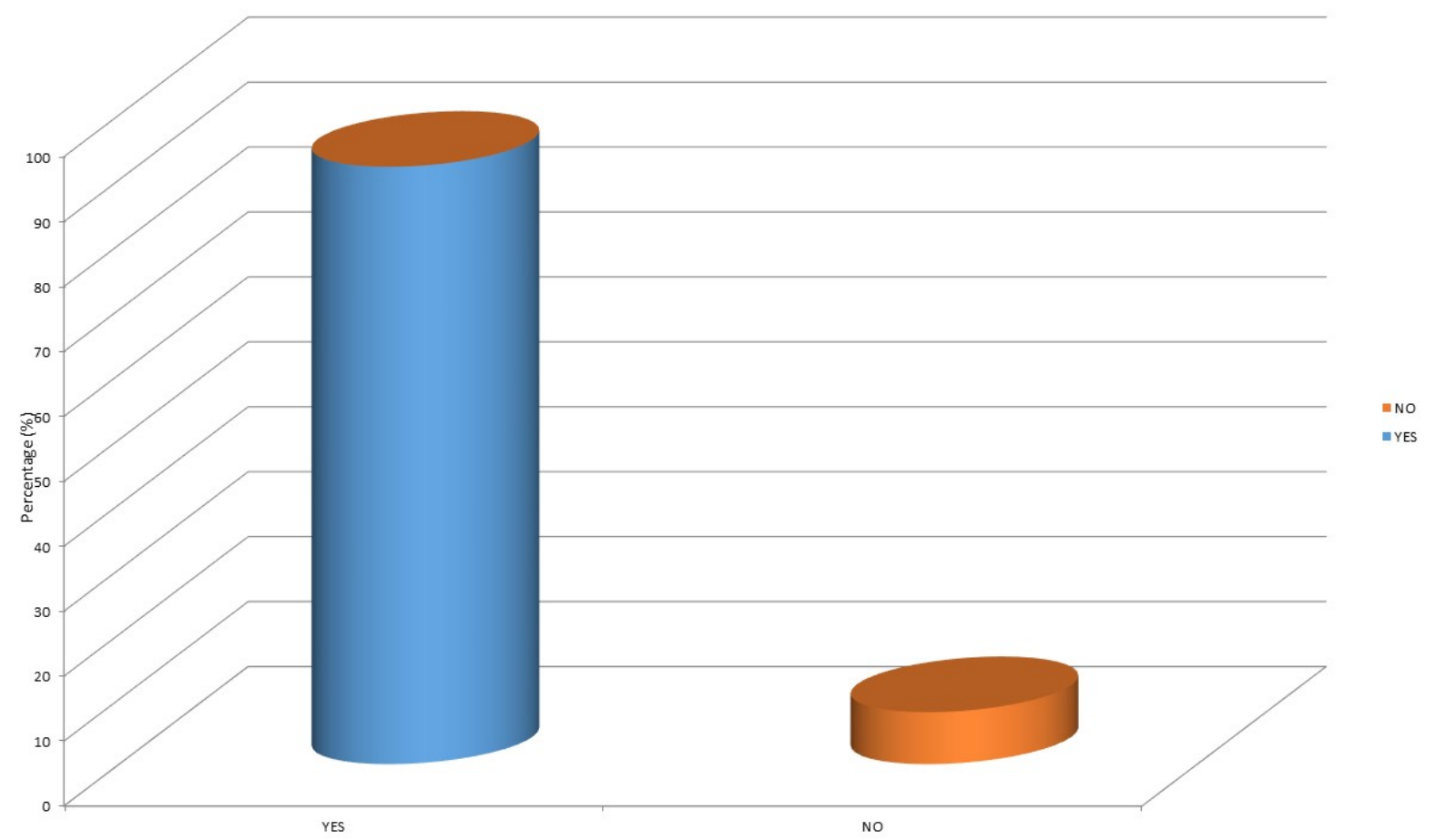

Chart 4. Whether information mothers have about ANC can help them in subsequent pregnancies

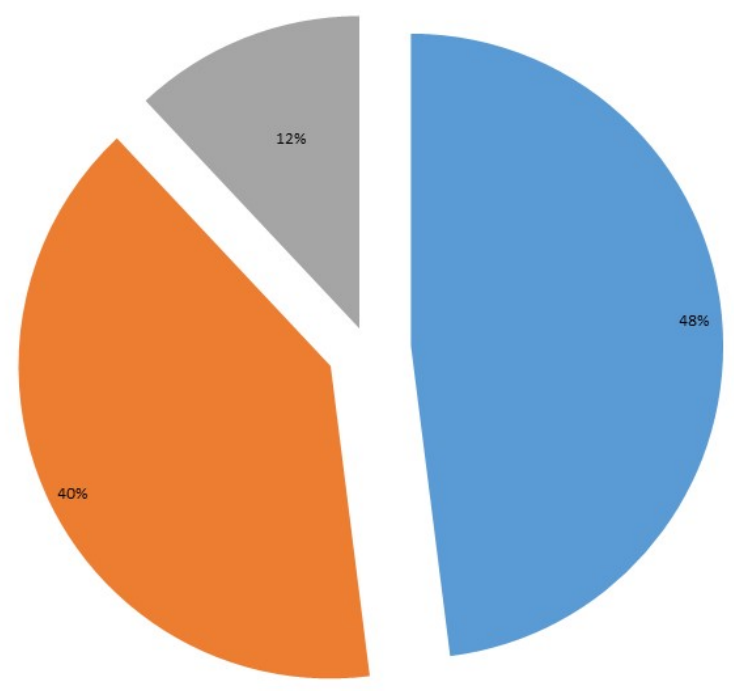

II No,they do not need if they are feeling healthy II yes, if they need to

=Am not sure

Chart 5. Whether multiparous pregnant women to attend ANC 
Table 5. Cadre of health workers of health workers offering ANC services at Kagote unit

\begin{tabular}{lll}
\hline Cadre & Frequency & Percentage (\%) \\
Midwives & 84 & 47 \\
Nursing officers & 44 & 24 \\
Student nurses and clinicians & 24 & 13 \\
Nursing assistants & 12 & 7 \\
Others & 16 & 9 \\
TOTAL & $\mathbf{1 8 0}$ & $\mathbf{1 0 0}$ \\
Some respondents gave more than 1 answer \\
\hline
\end{tabular}

Table 6. Showing the order of pregnancy at which pregnant women attend ANC

\begin{tabular}{lll}
\hline Order of pregnancy & Frequency & Percentage \\
$1^{\text {st }}$ & 50 & 40 \\
$2^{\text {nd }}$ & 30 & 30 \\
All pregnancies & 8 & 8 \\
Am not sure & 12 & 12 \\
TOTAL & $\mathbf{1 0 0}$ & $\mathbf{1 0 0}$ \\
\hline
\end{tabular}

A half of the respondents $50(50 \%)$ reported that ANC should be attended in the first pregnancy while only $8(8 \%)$ reported in all pregnancies. The rest were as in the table above.

The respondents reported the following challenges;

- Long distance from ANC clinic 32(13\%)

- Harsh health service providers 8(3\%)

- Lack of enough support from husbands 22(9\%)

- Segregation and discrimination 12(5\%)

- Negative attitude towards ANC by some family members $16(7 \%)$

- High transport costs 37(15.4\%)

- Lack of enough money $43(18 \%)$

- Lack of enough time 10(4\%)

- Unavailability of some drugs at times $24(10 \%)$

- Too much work load at home $16(7 \%)$

- Long waiting time at the ANC clinic 20(8.3\%)

\section{DISCUSSION, CONCLUSION, AND RECOMMENDATIONS}

\section{Discussion}

Demographic factors affecting ANC attendance

Age

From the study, many of the respondents 28 (28\%) were between the ages $25-29$ years followed by $20(20 \%)$ in the age group of $30-34$ years, only
$10(10 \%)$ were in the age group 15-19 years and the least $4(4 \%)$ were in the age group of $45-49$ years. This is in line with Peter et al., (2014) who stated that teenage respondents are poor seekers of ANC and also agrees with Dairo et al., (2010) who found that women who are 25 years or more are more likely to attend ANC clinic than those below 25 years. It also agrees with King'oo et al., (2015) who revealed that the least attendance of ANC was in those above 45 years. These findings can be explained by the fact that most of the married women and those in strong relationships are between the ages of 25-34 years and are more concerned about their health than the younger and the older respondents.

\section{Ethnicity}

The majority of the respondents 40 (40\%) were Batooro, followed by Bakonzo at 24 (24\%). This disagrees with King'oo et al., (2015) who stated that women view attending ANC clinic as a taboo despite knowing these services. In my opinion, the high percentage of the Batooro could be because they are the indigenous culture in the region and not because they have better cultural views or fewer taboos on pregnancy and ANC. Therefore, culture is not a barrier to ANC attendance.

\section{Religion}

The highest percentage $36 \%$ of respondents were catholic, followed by Anglicans at $28 \%$ and Muslims were the least at $12 \%$. This strongly dis- 
agrees with Dairo et al., (2010) who suggested that in his study, Christians were less likely to attend ANC than Muslims. This can be explained by the fact that the study area is comprised of more Christians than Muslims and it has also been observed that Christians always give health education to the church members including ANC attendance.

\section{Marital status}

Seventy-six (76\%) of the respondents were married, $6(6 \%)$ were single, $2(2 \%)$ were widowed and a significant figure of $16(16 \%)$ were divorced. In agreement with this study, Simkhada et al., (2008) found out that most of the women who did not use ANC services were single. This could be because most single mothers had less support and encouragement from partners on ANC attendance. It may also be because most of the people who reported to be single were students therefore probably lacking knowledge on ANC. The widowed respondents reported that they had recently lost their husbands.

\section{Occupation}

Most of the respondents 32 (32\%) reported to be housewives, 28 (28\%) were peasants and 16 (16\%) were civil servants. This agrees directly with Peter et al., (2010) who stated that the majority of the women attending ANC tend to be housewives without independent and stable financial resources or positions. He also added that the difference in occupation influences time availability for access to ANC services. This particular point can explain the low 16 (16\%) number of civil servants. Due to the low economic status of the area, the number of housewives attending ANC was found to be higher than the number of civil servants.

\section{Level of education}

Nearly half 40 (40\%) of the respondents had attained secondary education followed by those who had attained primary level at $21(21 \%)$, only 15 (15\%) had attained tertiary level and a significant number of $12(12 \%)$ never attended any formal education. This agrees with Yang et al., (2010) who suggested that educated women were 6.8 more times more likely to receive ANC than those who were not educated and also agrees with Zeine et al., (2010) who reported that mothers who attained a primary level of education were more likely to attend ANC than women who were not able to read and write. However, it also disagrees with Yang et al., (2010) who stated that highly knowledgeable women were 6.5 times more likely to attend ANC as seen by the lower percentage of $15 \%$ of those who attained tertiary level. From my point of view, most of the residents in the study area have a low level of education and so low levels of income, making them seek care from the nearest health care center, also, people in the study area lack adequate knowledge about ANC since their level of education is generally low.

\section{Address}

More than half $56(56 \%)$ of the respondents were living in rural (village) areas, $32(32 \%)$ lived in the small town, and only 12 (12\%) from large towns. This disagrees with Yang et al., (2010) who stated that living in rural areas is associated with low attendance of ANC compared to living in urban areas. This can be explained by the fact that the health facility is in a local setting making it accessible to the local people in the area. The significant number 12 (12\%) could be explained by the traditional practice in Africa of women moving back from urban areas to their parents in the rural areas when pregnant or when nearing the time of delivery.

\section{Provider-related factors affecting ANC atten- dance}

\section{Number of health workers offering health services}

More than half of the respondents $56(56 \%)$ reported two health workers attending to them and 20 (20\%) reported 1 health worker. 84 (47\%) were midwives, 44 (24\%) were nursing officers, 16 (9\%) were other health workers' medical clinical officers, 24(13\%) were student nurses and clinicians and $12(7 \%)$ were nursing assistants. This agrees with Nouf et al., (2016) who indicated in his study that the number of medical doctors and physicians is limited; for there was no respondent reported a doctor or clinical officer as part of the health workers offering the service. From this study, the number of health workers was found to be adequate because the ANC clinic attended to at least 10-15 mothers on the ANC days that can easily be worked on by one midwife and health worker. However, the research study may also indicate that there is an inadequate quality of care because there were no specialists at the facility. This may force some mothers especially the highly educated not to seek ANC at the health facility.

\section{ANC service delivery}

From the study, most of the mothers reported that $40(40 \%)$ of the health workers were knowledgeable, 20 (20\%) were authoritative and 24 (24\%) 
were skilled. This is in line with Christopher et al., (2013) who said that health staff who provide ANC exercise significant authority, and mothers generally place their trust in their instruction. On skills and knowledge, Ahebaw et al., (2013) support that women who have confidence in skilled providers and their care tend to use services more, and also agrees with Peter et al., (2013) who found out that older women sought ANC from older health workers usually for fear of being attended to by young female health workers. Therefore, knowledge, authority, and skill influence ANC positively.

\section{Availability of materials to be used in the ANC clinic}

The majority of the respondents $82(59 \%)$ reported that essential drugs were always available at the clinic, $2(1.4 \%)$ reported they never got some medications (fansidar), and a significant number of the $18(13.1 \%)$ reported that they sometimes bought these drugs. The latter statement corresponds to the findings by Tetui et al., (2012) who stated that stock-outs are common occurrences especially in Ugandan public health facilities but disagrees with the same (Tetui et al., 2012) who revealed that the availability of essential drugs is generally poor in Ugandan public health facilities. The availability of essential drugs and other materials was therefore found to have a significant influence on ANC attendance. Majority of the respondents $72(30 \%)$ that reported services offered in ANC included routine physical examination $72(30 \%)$, medications 60(25\%), health education $40(17 \%)$ which are also included in Peter et al., (2010) and these were specific services like provision of preventive treatment such as iron, folic acid, and SP, provision of information.

\section{Other factors affecting ANC attendance}

Nearly a half $48(48 \%)$ of the respondents reported that multiparous women do not need to attend ANC if they are feeling healthy while $40(40 \%)$ of them reported that multiparous women should attend ANC if they need to. This corresponds to Christopher et al., (2013) who stated that multiparous women visited the clinic in later pregnancy, in some instances waiting up to the 9th month, their priority being to obtain the ANC card and they were less concerned about monitoring the progress of the pregnancy. In my own opinion, this is because they feel they know all about pregnancy and how to manage it. This is explained more by the respondents $23(92 \%)$ who reported that infor- mation mothers have on ANC can help them in the subsequent pregnancies.

Nearly half of the respondents $46(46 \%)$ reported that they were handled well by the health providers while a significant figure of $10(10 \%)$ were handled harshly. The latter statement corresponds to a study by Christopher et al., (2013) who stated that women feared being reprimanded by health care staff normally. Therefore, it is concluded that the good behaviour of the staff encourages ANC attendance and vice versa.

Nearly a half $50(50 \%)$ of the respondents reported that ANC should be attended in the 1st pregnancy, 32(32\%) in the 2nd pregnancy, and a significant number of $16(16 \%)$ in all pregnancies. This agrees with the research study by King'oo et al., (2015) who stated that ANC services are much more common for 1st pregnancies than subsequent pregnancies. The investigator's point of view is that this could be because they don't know much about pregnancy and its management in the first pregnancy and thus tend to attend ANC more at this time.

The challenge that affected ANC attendance as reported by the women $(43,18 \%)$ was a major lack of money, and this is well depicted by the number $37(15.4 \%)$ that reported transport costs as a challenge. This was in line with the study done by Pamela et al., (2005) that revealed lack of transport, employment status as some of the situational factors influencing ANC initiation. This could be so because most of the women in the study area are housewives.

On-time, 10(4\%) respondents reported that they didn't have enough time to attend ANC. This is in line with a research study by Zeine et al., (2010) who stated that women in developing countries spent more time on their multiple responsibilities for the care of children. In addition to that, this study also found that respondents $16(7 \%)$ reported too much workload at home as a challenge. This is because most of them were housewives and ran the daily activities in their homes.

The other challenges cited by the respondents were a long distance from ANC clinic 32(13\%); harsh health service providers $8(3 \%)$; lack of enough support from husbands 22(9\%); long waiting time at clinic 20(8.3\%), 12(5\%) reported segregation and discrimination and unavailability of some drugs at times 24(10\%). 


\section{Conclusion}

The majority of the respondents were between 2529 years and the minority were ages $45-49$. Old women are poor attendees because they feel they already know about pregnancy and how to manage it. Nearly half of the respondents were Batooro because it's the dominant ethnicity in the area. Most of them were Catholics, married, housewives, attained a secondary level of education, and live in villages.

The ANC services offered in Kagote $\mathrm{HCIII}$ include; routine physical examination of a pregnant woman, testing for HIV and syphilis, health education, tetanus vaccination, administration of medications like folic acid, fefan, mebendazole, fansidar, and others like amoxicillin although at times there are stock-outs which discourage ANC attendance.

ANC attendance is affected by health service providers: harsh providers decrease it while wellbehaved ones increase it; skilled, knowledgeable (cadre) and authoritative providers encourage attendance; an adequate number of them encourage attendance since the waiting time will be shorter and vice versa.

Pregnant women especially the multiparous already have information and experience about pregnancy and so they think it's not necessary to attend ANC unless they have a problem that they cannot handle. Order of pregnancy affects ANC attendance in such a way that women attend ANC for the first pregnancy well since they don't yet enough about it but for the subsequent pregnancies, their attendance decreases as explained in the former statement above.

The many challenges pregnant women face also discourage ANC attendance and these include lack of enough time, money, and support from their husbands, high transport costs, harsh health service providers, segregation and discrimination, too much workload at home, unavailability of drugs at times, long waiting time at clinic negative attitude by some family members, and long distance from the ANC clinic.

\section{Recommendations}

Basing on the study findings, to improve ANC attendance;

1. The $\mathrm{MOH}$ should continue sensitizing the people about the importance of ANC attendance.

2. Kagote HCIII should organize community outreaches to offer all the ANC services fully.
3. The health facility should collaborate with VHTs in encouraging pregnant women to attend ANC.

\section{Limitations and Delimitations}

Financial constraints for buying study materials and for other expenses during the research process. The investigator overcame this by requesting money from her parents to facilitate the research study.

Time allocated for the research project while other school activities go on, was limited. The investigator overcame this by budgeting her time appropriately between the research project and the school activities.

Some respondents most likely expected financial enticement. The investigator overcame this by explaining to the respondents that she was just a student in need of their help.

Dissemination of results

Original copy was submitted to Uganda Allied Health Examination Board.

One copy was submitted to Fort Portal School of Clinical Officers.

The investigator retained one copy.

\section{ACKNOWLEDGEMENT}

I acknowledge THE ALMIGHTY GOD for loving me and taking me through this research successfully, my supervisor Mr. Mpuhuuka Ezra for the guidance through this research study, the administration of Fort Portal School of Clinical Officers, and the incharge Kagote $\mathrm{HClll}$ for allowing me to research this health facility.

I also sincerely thank my parents- Mr. Luke Ouchokol and Mrs. Christine Ouchokol, my brothers - Omoding J, Inyalio M, Ouchokol M, Amunaun C, my uncle Odongo $B$ and my sisters- Akol $M$, Asio $F$, Sana F, my best friend Nabukko $P$ and all my friends, thank you for loving, supporting, guiding me in all and the prayers. May GOD richly bless you!

\section{LIST OF ABBREVIATIONS}

AHSPR: Annual Health Sector Performance Report ANC: Antenatal Care

DHS: Demographic and Health Survey

EMHS : Essential Supplies and Health Supplies 
FANC: Focused Antenatal Care

GoU: Government of Uganda

Gov't : Government

HIV : Human Immunodeficiency Virus

HSSIP : Health Sector Strategic Investment Plan

IPTp : Intermittent Preventive Treatment

ITNs : Insecticide Treated Nets

$\mathrm{MOH}$ : Ministry Of Health

$\mathrm{NIH}$ : National Institute of health

PMTCT: Prevention of Mother -To -Child Transmission

PPH : Post partum haemorrhage

SP : Sulphadoxine- pyrimethamine

SSA : Sub Sahara Africa

US: United States

WHO : World Health Organization

\section{References:}

1) Christopher P., Arantza M., Florence W., Nana A., Afrah, S. C., Lucinda M.T., Mary J. H., Abraham H., Harry T., Linda K., Peter O., \& Robert P. (2013) Factors affecting ANC attendance: Results from Qualitative studies in Ghana, Kenya, and Malawi. PLOS ONE 8 (1): e53747. Doi 10.1371/ journal.pone: 0053747 https://doi.org/10.1371/journal.pone.00 53747 PMid:23335973 PMCid:PMC3546008

2) District planning unit- Kabarole 2010/ 2011 2012/ 2013.

3) Jennifer H., Jennifer JK., Laura O., Peter B., \& Ron G. (2009). A systematic review of antenatal care programs to reduce infant mortality and its major causes in socially disadvantaged and care vulnerable. National Perinatal Epidemiology Unit, University of Oxford. Page 6- 8.

4) King'oo B. M. (2015) Factors affecting attendance to Antenatal care services in Kenya, the case study of Somali women in Eastleigh Nairobi County, Kenya.

5) MD Dairo \& KE Owoyokun (2010) Factors affecting the utilization of antenatal services in Ibadan, Nigeria. https://doi.org/10.4314/bjpm.v12i1.6338 7

6) Moses T., Elizabeth K. E., Aloysius M., Raymond T., \& Waiswa .P. (2012) Quality of antenatal care services in Eastern Uganda: implications of interventions. The Pan African Medical Journal 13.27 doi: 10.11604/ pamj. 2012. Page 1427

7) Nouf A. A., Ayman A.B., Sondos A. A., Zina A. Z., Esraa A. A., \& Osama S., B.(2016) Obstacles affecting antenatal care attendance. Results from a cross sectional study in Jeddah, Saudi Arabia page 213219

8) Pamela L., Janis P., Trecia W., Sarnia C., Maynard W., \& Teuila P. (2005). Factors affecting antenatal care attendance by mothers of Pacific infants living in New Zealand. The New Zealand Medical Journal. Volume 118 page 1- 10

9) Peter O. O., Anna M. V. E., Mary J. H., Evallyne S. S., Frank O.O., Kaendi M. M., John G . A., Sara B.C., Piet A.K., \& Laurence S. (2010) Reproductive Health 7:1 page 5

10) Peter R. A., \& Kenneth M. (2014) Influence of pregnancy perceptions on patterns of seeking antenatal care among women in reproductive age of Masaka district, Uganda . Tanzania Journal of health Research. Page 8-9 https://doi.org/10.4314/ thrb.v16i4.8 PMid:26891521

11) Simkhada B., Teijlingen E.R., Porter M., \& Simkhada P (2008). Factors affecting the utilization of antenatal care in developing countries: systematic review of the literature https://doi.org/10.1111 /j.1365-2648.2007.04532.x PMid:18197860

12) St. Mary's Midwifery Training School. (2013) Survey of factors affecting fourth ANC visits in Dr. Ambrosoli Memorial Hospital- Agago District.

13) Toan K T., Karin G., Hinh DN., Henry A., \& Max P. (2012) Factors associated with adequacy in adequacy in rural and urban contexts. Results from two health and demographic surveillance sites in Vietnam.12:40 https://doi.org/10.1186/14 72-6963-12-40 https://doi.org/10.1186/1472-696312-40 PMid:22335834 PMCid:PMC3305637

14) Uganda Bureau of statistics (UBOS) \& Macro International Inc. (2007) Uganda Demographic and Health Survey 2006. Calverton: UBOS and Macro International Inc.

15) World Health Organization. (2010) Packages of interventions for Family Planning, Safe Abortion care, Maternal, Newborn and Child HealthPackages of Interventions https://www.who.int/pmnch/activi ties/jointactionplan/srhp_packages.pdf

16) Yang Y., Yushitoku Y., Harun R., \& Junichi Sakamato. (2010) factors affecting the utilization of antenatal care services among women in Kham district, Xiengkhouang Province Lao PDR. Journal of Medical Science; 72(1- 2):23- 33

17) Yifru B., \& Asres B. (2014) Antenatal Care as a means of increasing birth in the health facility and reducing maternal mortality. A systematic review.24: 93- 104 https://doi.org/10.4314/ejhs.v24i0. 9S PMid:25489186 PMCid:PMC4249212 
18) Zeine A., Mikuzie W., \& Shimeles O. (2015) Factors influencing Antenatal care utilization in Hadiya zone. 20(2): 75- 82 https://doi.org/10.4314/ejhs.v2

0i2.69432 PMid:22434964 PMCid:PMC3275839 